\title{
Occurrence frequency of convective gravity waves during the North American thunderstorm season
}

\author{
L. Hoffmann ${ }^{1}$ and M. J. Alexander ${ }^{2}$ \\ Received 21 April 2010; revised 18 June 2010; accepted 23 July 2010; published 22 October 2010.
}

[1] Convective gravity waves are an important driver of the equator-to-pole circulation in the stratospheric summer hemisphere, but their nature is not well known. Previous studies showing tight relationships between deep convection and convective waves mainly focus on tropical latitudes. For midlatitudes most analyses are based on case studies. Here we present a new multiyear occurrence frequency analysis of convective waves at midlatitudes. The study is based on radiance measurements made by the Atmospheric Infrared Sounder (AIRS) satellite experiment during the North American thunderstorm season, May to August, in the years 2003-2008. For this study we optimized an existing algorithm to detect deep convection in AIRS data to be applicable at midlatitudes. We also present a new detection algorithm for gravity waves in AIRS data based on a variance filter approach for $4.3 \mu \mathrm{m}$ brightness temperatures. The new algorithm can detect plane wave perturbations in the altitude range from 20 to $65 \mathrm{~km}$ with vertical wavelengths larger than $15 \mathrm{~km}$ and horizontal wavelengths from 50 to $1000 \mathrm{~km}$. By analyzing spatial and temporal correlations of the individual AIRS observations, it can be shown that more than $95 \%$ of the observed gravity waves in a core region over the North American Great Plains are related to deep convective clouds, i.e., are likely being classified appropriately as convective waves. We conclude that the core region is a good location to observe and characterize the properties of convective waves at midlatitudes. The statistical analyses presented here are also valuable to validate parameterization schemes for convective gravity waves. For completeness, it should be mentioned that our analyses cover not only the U.S. Midwest but the North American continent as well as the surrounding ocean regions in general. Our analysis also reveals interesting details about tropical convection and related gravity wave activity, as well as the capability of the AIRS instrument to observe these.

Citation: Hoffmann, L., and M. J. Alexander (2010), Occurrence frequency of convective gravity waves during the North American thunderstorm season, J. Geophys. Res., 115, D20111, doi:10.1029/2010JD014401.

\section{Introduction}

[2] The meridional circulation in the middle atmosphere is mainly driven by wave activity. The summer- to winterpole circulation in the mesosphere is governed by gravity wave activity [Holton, 1982, 1983]. The equator-to-pole circulation in the stratospheric winter hemisphere is controlled by planetary wave activity [e.g., Andrews et al., 1987]. In contrast, the circulation in the stratospheric summer hemisphere is driven in part also by gravity waves [Alexander and Rosenlof, 1996; Scaife et al., 2000].

[3] Westward winds throughout the summer middle atmosphere prevent the penetration of stationary planetary waves and mountain waves, and by many measures, this region of the atmosphere is considered a quiet region, with

\footnotetext{
${ }^{1}$ Institut für Chemie und Dynamik der Geosphäre, Forschungszentrum Jülich, Jülich, Germany.

${ }^{2}$ Colorado Research Associates Division, NorthWest Research Associates, Inc., Boulder, Colorado, USA.

Copyright 2010 by the American Geophysical Union. 0148-0227/10/2010JD014401
}

relatively weak wave activity. This is well confirmed by rocket and radiosonde observations [e.g., Hirota, 1984; Hamilton, 1991; Allen and Vincent, 1995; Eckermann et al., 1995; Wang and Geller, 2003] as well as satellite data [e.g., Ern et al., 2004; Alexander et al., 2008]. The nature of the waves assumed to drive the middle atmosphere residual circulation in the summer midlatitude and high latitude remains poorly known.

[4] It is known, though, that deep convection is an important source mechanism for gravity waves at tropical latitudes and to a less extent also at midlatitudes. Comprehensive global circulation modelling studies by Beres et al. [2005], using an entirely theoretical parameterization scheme for convectively generated gravity waves, show the importance of these waves at both low latitude and midlatitude. Observations generally show close correspondence of gravity waves with deep convective clouds. Most of these studies have shown relationships between deep convection and gravity waves at low latitudes [e.g., Larsen et al., 1982; Pfister et al., 1986, 1993; Alexander and Pfister, 1995; Dewan et al., 1998; McLandress et al., 2000; Alexander et al., 2000; Dhaka et al., 2005; Kumar, 2007; Dutta et al., 2009; 
Grimsdell et al., 2010], but some case studies have also been presented for midlatitudes [e.g., Sato, 1992, 1993; Sato et al., 1995].

[5] While previous studies are mostly based on individual cases, here we present a new multiyear occurrence frequency analysis of convective waves at midlatitudes. The focus of this study is on the North American thunderstorm season, i.e., the time period from May to August each year, during which deep convection as well as convective waves occur frequently. The analysis is based on observations from the Atmospheric Infrared Sounder (AIRS) satellite experiment, described in section 2. In section 3, a detection method for deep convection events based on AIRS radiance measurements is outlined. This section also presents the occurrence frequency of deep convection during the North American thunderstorm season based on a 6 year time period (20032008). Section 4 describes a new fast detection algorithm for gravity waves from AIRS measurements. Occurrence frequencies of gravity waves over the North American continent are presented as well. In section 5 we discuss the spatial and temporal correlations of deep convection and gravity waves. Conclusions and outlook are found in section 6 of this paper.

\section{AIRS Instrument}

[6] On 4 May 2002 the National Aeronautics and Space Administration (NASA) launched the Aqua satellite [Parkinson, 2003] aboard a Delta II rocket from Vandenberg Air Force Base, California, United States. The Aqua mission is a part of the NASA-centered international Earth Observing System (EOS). Aqua is the first satellite in the "A-Train" constellation of satellites. Six instruments on board Aqua monitor the global state of the Earth's atmosphere. The Atmospheric Infrared Sounder (AIRS) [Aumann et al., 2003] measures the thermal emissions of atmospheric constituents in the nadir and sublimb observation geometry.

[7] Aqua operates at $705 \mathrm{~km}$ altitude in a Sun-synchronous polar orbit with $98^{\circ}$ inclination and 99 min period. The equatorial crossing occurs at 0130 (descending orbit) and 1330 (ascending orbit) local time (LT). Global coverage is achieved during 14.5 orbits per day. The AIRS aperture is $1.1^{\circ}$, corresponding to a footprint diameter of $13.5 \mathrm{~km}$ in the nadir. A rotating mirror is used to carry out sublimb scans in the across-track direction. An AIRS "scan" consists of 90 individual footprints and covers an across-track distance of $1650 \mathrm{~km}$ on the ground $\left( \pm 48.95^{\circ}\right.$ in scan angle). A scan is measured in $2.667 \mathrm{~s}$. The along-track distance between two scans is $18 \mathrm{~km}$. The AIRS measurements are gathered in "granules." Each granule covers six minutes of measurement time, i.e., 135 scans or 12150 footprints. The along-track size of a granule is $2400 \mathrm{~km}$.

[8] The AIRS spectral measurements cover the wavelength ranges 3.74 to $4.61 \mu \mathrm{m}, 6.20$ to $8.22 \mu \mathrm{m}$, and 8.8 to $15.4 \mu \mathrm{m}$. A diffraction grating disperses the scene radiance onto 17 linear arrays of $\mathrm{HgCdTe}$ detectors, providing a total of 2378 radiance channels. The nominal resolving power of the hyperspectral infrared radiometer is $\lambda / \Delta \lambda=1200$. The processing of instrument raw data into calibrated radiance spectra and corresponding geolocation data is described in detail by Aumann et al. [2000], Pagano et al. [2003], Aumann et al. [2006a], Nalli et al. [2006], Tobin et al. [2006], and
Walden et al. [2006]. The analyses presented in this paper are based on consolidated Level 1B data products made publicly available by NASA (processing software version 5.x).

[9] The AIRS instrument provides nearly continuous measurement coverage since September 2002. During a single day AIRS measures about 2.9 million radiance spectra globally. Our analysis of gravity waves and deep convection covers the North American continent $\left(45\right.$ to $145^{\circ} \mathrm{W}, 10$ to $70^{\circ} \mathrm{N}$ ) and the Midwest thunderstorm season from start of May to end of August during the years 2003 to 2008. For this study we analyzed 190 million individual AIRS radiance spectra.

[10] The detection methods for gravity waves and deep convection are illustrated in Figure 1. The algorithms are discussed in detail in section 3 and 4. Figure 1a shows brightness temperature perturbations for the $4.3 \mu \mathrm{m}$ spectral region. Being dominated by the $\mathrm{CO}_{2} \nu_{3}$ fundamental band, the atmosphere becomes opaque in this spectral region around 30 to $40 \mathrm{~km}$ altitude. Since the $4.3 \mu \mathrm{m}$ brightness temperature perturbations are directly related to stratospheric temperature perturbations the corresponding AIRS channels can be used to detect stratospheric gravity waves. As illustrated in Figure 1b we apply a variance filter for this purpose. In order to detect deep convection events $8.1 \mu \mathrm{m}$ radiance measurements are analyzed (Figure 1c). In this spectral region the atmosphere is nearly transparent. For cloud-free conditions the $1231 \mathrm{~cm}^{-1}$ AIRS radiance channel is dominated by surface emissions. Optically thick clouds are detected based on considerably reduced brightness temperatures due to cold cloud temperatures at upper altitudes in the troposphere and lower stratosphere. As illustrated in Figure 1d, the AIRS measurements can be used to detect gravity waves and deep convection simultaneously in the same footprint.

\section{Observations of Deep Convection}

\subsection{Mesoscale Convective Systems}

[11] Thunderstorms thrive on warm, moist, unstable air and are triggered by lift. The latter may be provided by an approaching cold front or an upper level low. In the North American Midwest the thunderstorm season begins in late April and continues till early September. During the thunderstorm season a southerly low-level jet moves farther north, so that warm and moist air from the Gulf of Mexico can invade inner continental regions. The moist air feeds thunderstorms which develop in advance of Pacific cold fronts. The thunderstorms cluster in swaths, oriented southwest to northeast, and move northeastward ahead of the fronts. A typical example of such a thunderstorm cluster can be seen in Figure 1c southwest of the Great Lakes.

[12] Over the Great Plains organized systems of thunderstorms known as mesoscale convective systems (MCS) develop during May to August. The bulk of MCS activity occurs between 0000 and 0600 LT. Due to the west-to-east propagation of the MCS the maximum precipitation typically occurs at the Rocky Mountains slopes in late afternoon and at early morning in the Ohio River valley [Carbone et al., 2002; Ahijevych et al., 2004]. MCS cause 30 to $70 \%$ of the annual warm season rainfall in the Great Plains.

[13] Mesoscale convective complexes (MCC) are an especially large and long-lived type of MCS, accounting for 8 to $18 \%$ of the annual warm season rainfall across the Midwest [Ashley et al., 2003]. Maddox [1980] defines the MCC 
a)
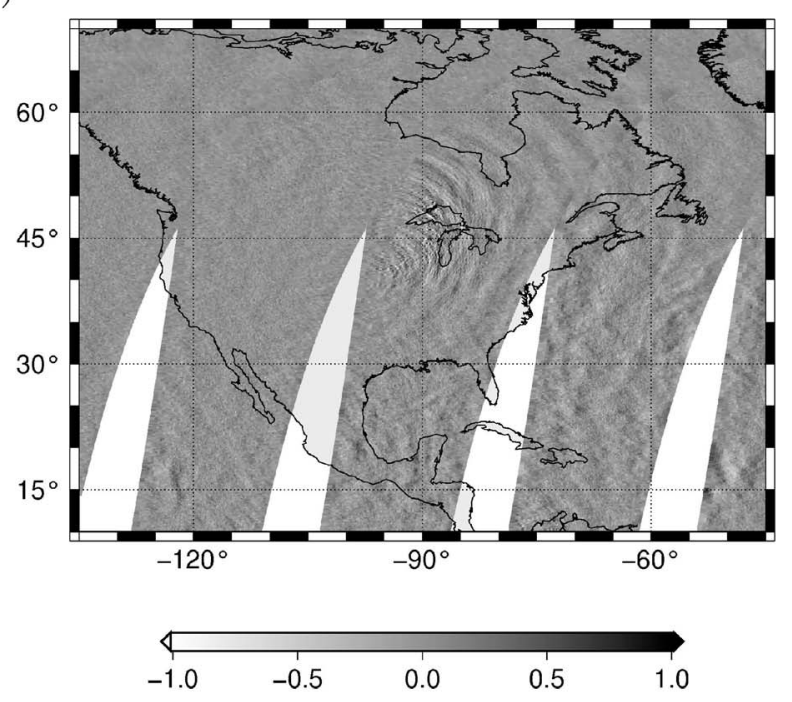

c)

brightness temperature perturbation (4 micron) [K]

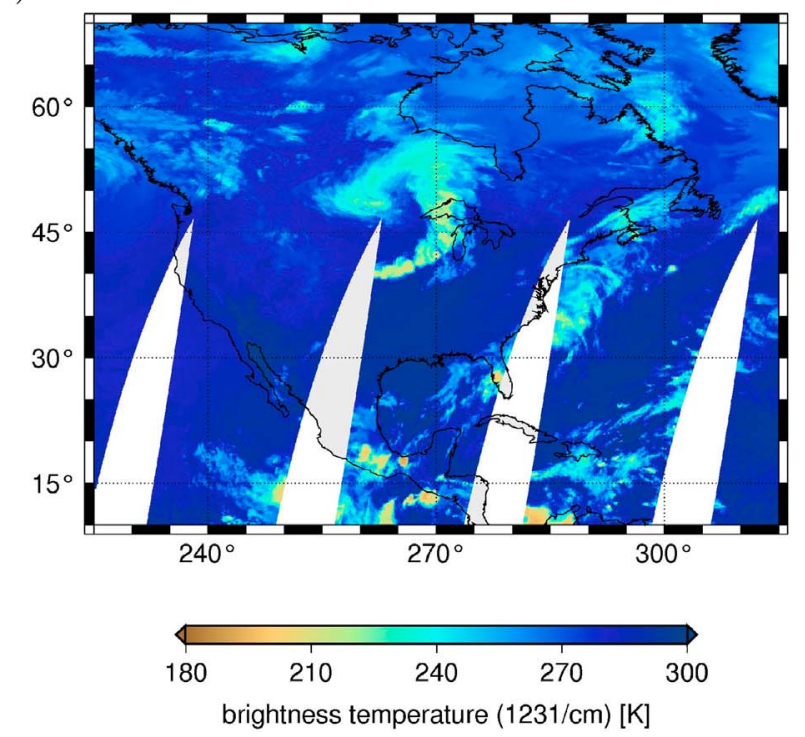

b)

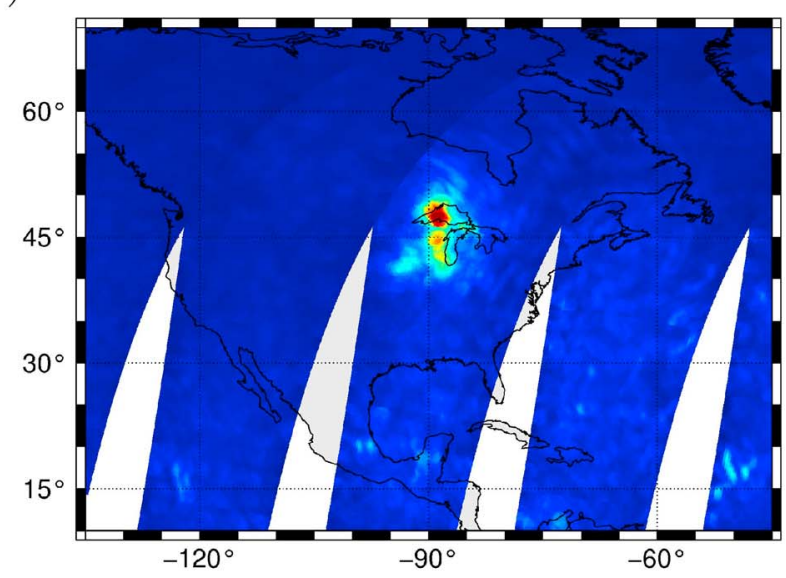

d)

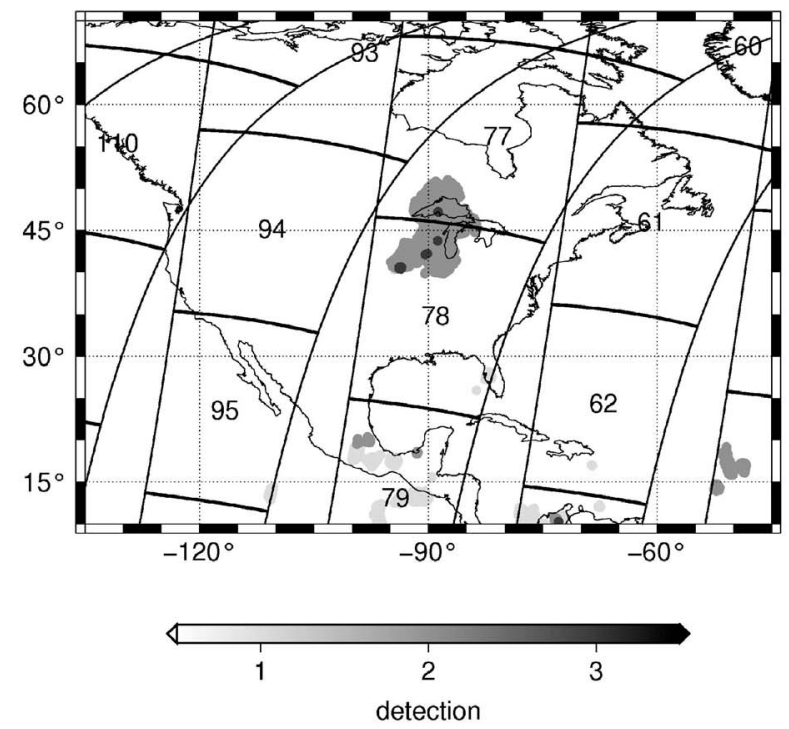

Figure 1. Detection of gravity waves and deep convection from AIRS radiance measurements for 30 June $2005,0130 \mathrm{LT}$. (a) Brightness temperature perturbations in the $4.3 \mu \mathrm{m}$ spectral region indicating gravity wave activity. (b) Results of a variance filter applied to the $4.3 \mu \mathrm{m}$ brightness temperature perturbations. (c) Brightness temperatures at $8.1 \mu \mathrm{m}$ indicating clouds and deep convection. (d) Detection results for deep convection (light gray dots), stratospheric gravity waves (medium gray dots), and simultaneous occurrence in the same AIRS footprint (dark gray dots). Similar plots for the entire time period analyzed are made available electronically at https://simlab.icg.kfa-juelich.de/airs.

based on analyses of enhanced IR satellite imagery. In this definition, a MCC must have a continuous cold cloud shield with IR temperatures below $241 \mathrm{~K}$ and an area greater than $100,000 \mathrm{~km}^{2}$, plus an interior cold cloud region with IR temperatures below $221 \mathrm{~K}$ with an area greater than $50,000 \mathrm{~km}^{2}$. Both the continuous cold cloud shield and the interior cold cloud region must also be present for a period of $6 \mathrm{~h}$ or longer.

\subsection{Detection Method for Deep Convection}

[14] Thunderstorms can be detected in IR satellite imagery based on low brightness temperatures in spectral window regions. Aumann et al. [2006b] use the $1231 \mathrm{~cm}^{-1}$ AIRS radiance channel in nonpolar areas, i.e., for latitudes below $\pm 60^{\circ}$, and a temperature threshold of $210 \mathrm{~K}$ to detect deep convection events in AIRS observations. Since the size of the AIRS footprint at nadir is only $13.5 \mathrm{~km}$, a brightness temperature of less than $210 \mathrm{~K}$ indicates that the top of the anvil of the thunderstorm protrudes well into the tropopause region. Such objects are commonly referred to as deep convective clouds. On a global basis, Aumann et al. [2006b] identified about 6000 large thunderstorms in the AIRS data each day, almost exclusively within $\pm 30^{\circ}$ of the equator. 
[15] For this study we use the $1231 \mathrm{~cm}^{-1}$ AIRS radiance channel suggested by Aumann et al. [2006b] to identify deep convection events. However, a threshold of $210 \mathrm{~K}$ was found to be too conservative to identify all events at midlatitudes. The mean tropopause temperature is $197 \mathrm{~K}$ in the tropics but is only as low as $215 \mathrm{~K}$ at midlatitudes [Remedios et al., 2007]. Based on these temperature values we increased the threshold to detect deep convection to $220 \mathrm{~K}$. It corresponds better to the Maddox [1980] definition of the MCC (see section 3.1). The average atmospheric temperature first drops below $220 \mathrm{~K}$ at $13 \mathrm{~km}$ altitude in the tropics and at $12 \mathrm{~km}$ at midlatitudes. In the polar regions the mean tropopause temperature is about $195 \mathrm{~K}$ in winter and $221 \mathrm{~K}$ in summer. These temperatures are first observed at 8 and $10 \mathrm{~km}$ altitude, respectively.

\subsection{Occurrence Frequency of Deep Convection}

[16] AIRS observations over the North American continent during the years 2003 to 2008 are analyzed to determine the occurrence frequency of deep convection events during the annual Midwest thunderstorm season, i.e., for the time period from start of May to end of August. The occurrence frequency is obtained as the ratio of the number of footprints with detected deep convection events (see section 3.2) with respect to the total number of observations. To take into account the different local times the data are analyzed separately for the ascending orbits (daytime, about $1330 \mathrm{LT}$ ) and descending orbits (nighttime, about 0130 LT). Data are analyzed on a $1^{\circ} \times 1^{\circ}$ longitude-latitude grid. The total number of observations within each grid box increases from 33,000 at $10^{\circ} \mathrm{N}$ to 38,000 at $70^{\circ} \mathrm{N}$.

[17] The maps of occurrence frequency presented in Figure 2 show several distinct features. First, most deep convection events are identified in the thunderstorm areas at tropical latitudes. Locally, occurrence frequencies are as high as (18 \pm 4$) \%$ during nighttime and $(19 \pm 6) \%$ during daytime. The errors reported here represent one standard deviation. During the nighttime the highest occurrence frequencies are found at the west coast of Central America. During the daytime the patterns change and maximum occurrence is found over the Pacific Ocean and at the east coast of Nicaragua. Second, we find increased deep convection activity, i.e., about 4 to 7\%, at the Yucatan Peninsula, the west coast of Cuba, the Dominican Republic, Florida, and at the U.S. coasts of the Mexican Gulf. These features are more pronounced during the daytime. Yearly variability is largest over the Caribbean Sea (standard deviation up to 4\%). Third, another very distinct pattern of enhanced deep convection activity is present over the North American Great Plains. Being related to MCS activity (section 3.1) this pattern is most pronounced in the nighttime measurements. Maximum occurrence frequencies are about $(6 \pm 2) \%$ and occur near 35 to $45^{\circ} \mathrm{N}$ and 90 to $100^{\circ} \mathrm{W}$. In this paper we focus on the Midwest pattern of deep convection activity and study its impact on gravity wave generation.

\section{Observations of Gravity Waves}

\subsection{Convectively Generated Gravity Waves}

[18] Deep convection is an important source of gravity waves. Numerical simulations with high spatial resolution show that isolated deep convective systems strongly force short horizontal wavelengths [e.g., Piani et al., 2000; Lane et al., 2001]. Circular wave fronts like the ones predicted by convective models have been observed in satellite sublimb data and in mesosphere and lower thermosphere airglow imagery [e.g., Taylor et al., 1987; Taylor and Hapgood, 1988; Dewan et al., 1998; McLandress et al., 2000; Sentman et al., 2003; Suzuki et al., 2007; Hecht et al., 2009]. The concentric semicircular arc patterns in the summertime stratosphere over North America such as shown in Figure 1a are very similar to these modeled and observed patterns associated with waves generated by convection. While for most studies the correlation between gravity waves and deep convection is based on circumstantial evidence, Grimsdell et al. [2010] recently modeled in detail a particular gravity wave event observed by AIRS, where the model was forced by individual convective sources observed by radar. Studies with other models and mechanisms of gravity wave generation by deep convection predict the generation of longer horizontal wavelength waves [e.g., Salby and Garcia, 1987; Pfister et al., 1993]. Such waves have also been observed in in-situ measurements and from satellites [e.g., Pfister et al., 1993; Preusse et al., 2001; Jiang et al., 2004; Preusse and Ern, 2005].

\subsection{Detection Method for Gravity Waves}

[19] The occurrence of stratospheric gravity waves can be detected directly from AIRS radiance measurements in spectral regions that become opaque in the stratosphere and which are dominated by radiance emissions of a trace gas with constant volume mixing ratio. For this study we select 42 AIRS channels (2322.6 to $2366.9 \mathrm{~cm}^{-1}$ ) from the $4.3 \mu \mathrm{m}$ $\mathrm{CO}_{2} \nu_{3}$ fundamental band. Detailed tests show that all selected channels are neither influenced by interfering species nor by the presence of clouds [e.g., Hoffmann and Alexander, 2009]. It should be pointed out that the $4.3 \mu \mathrm{m}$ radiance measurements are influenced by non-LTE effects due to solar excitation at daytime. However, we conclude that these effects do not significantly affect the detection algorithms presented in this study. The $15 \mu \mathrm{m} \mathrm{CO} \nu_{2} \nu_{2}$ fundamental band, also captured by the AIRS instrument, would provide another option for gravity wave detection. However, the number of suitable stratospheric channels is rather limited compared with the $4.3 \mu \mathrm{m}$ region. An advantage of the $4.3 \mu \mathrm{m}$ radiance measurements is that these are more sensitive to temperature changes as the Planck function is more sensitive to temperature changes at shorter wavelengths.

[20] To reduce noise, a rather large number of AIRS radiance channels were selected for the analyses. The brightness temperatures of the individual channels are averaged for each footprint. To obtain the temperature kernel function for the mean brightness temperature the temperature kernel functions of the individual channels need to be averaged. Figure 3 shows the mean and individual kernel functions computed for midlatitude atmospheric conditions. The individual AIRS channels are selected in order to have similar kernel functions in terms of peak height and full-width at half-maximum (FWHM). The mean kernel function has a broad maximum around 30 to $40 \mathrm{~km}$ altitude and a FWHM of $25 \mathrm{~km}$. The mean brightness temperature will be sensitive to temperature changes within the 20 to $65 \mathrm{~km}$ altitude range. The lower boundary of $20 \mathrm{~km}$ is well above the tropopause and ensures 
a)

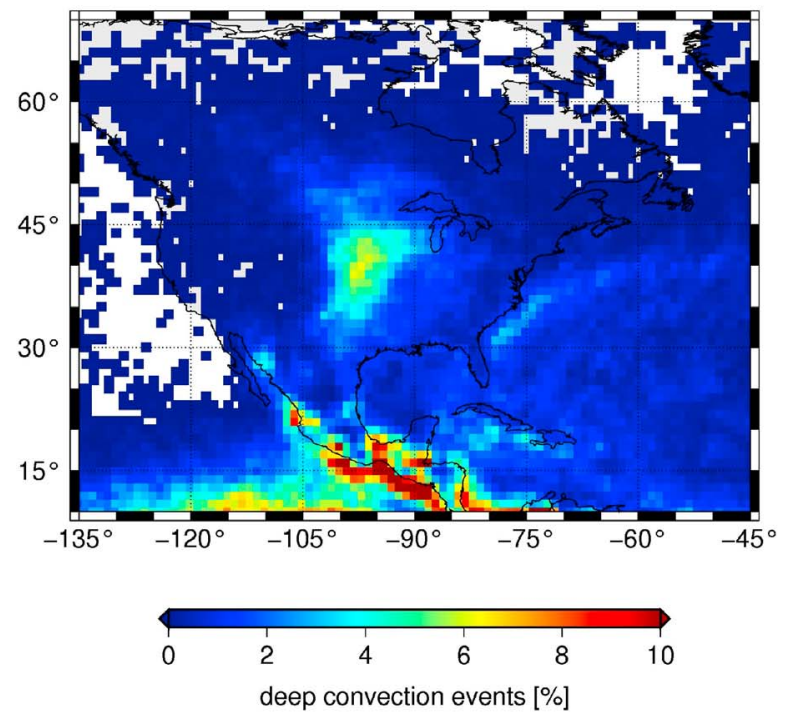

c)

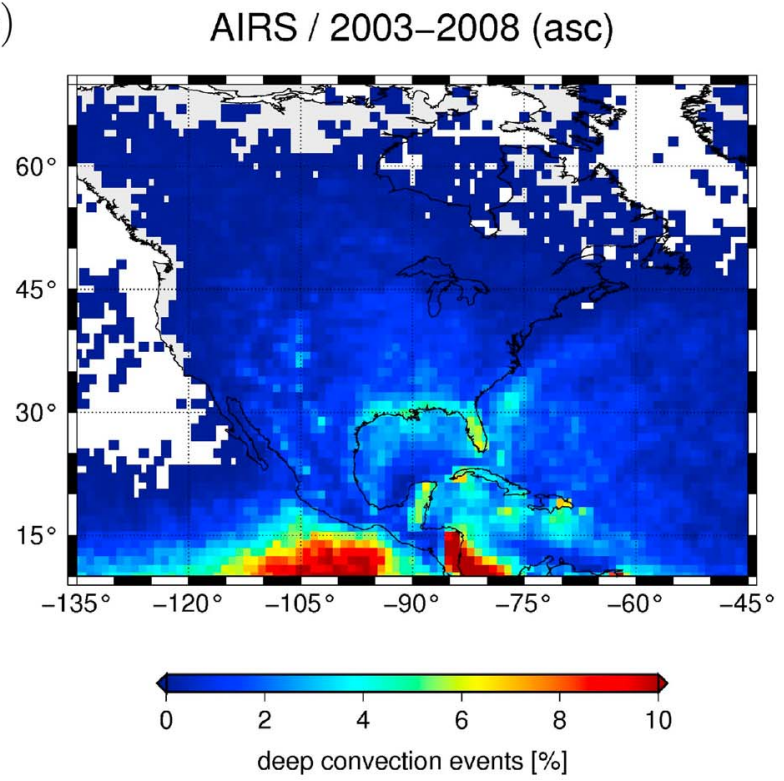

b)

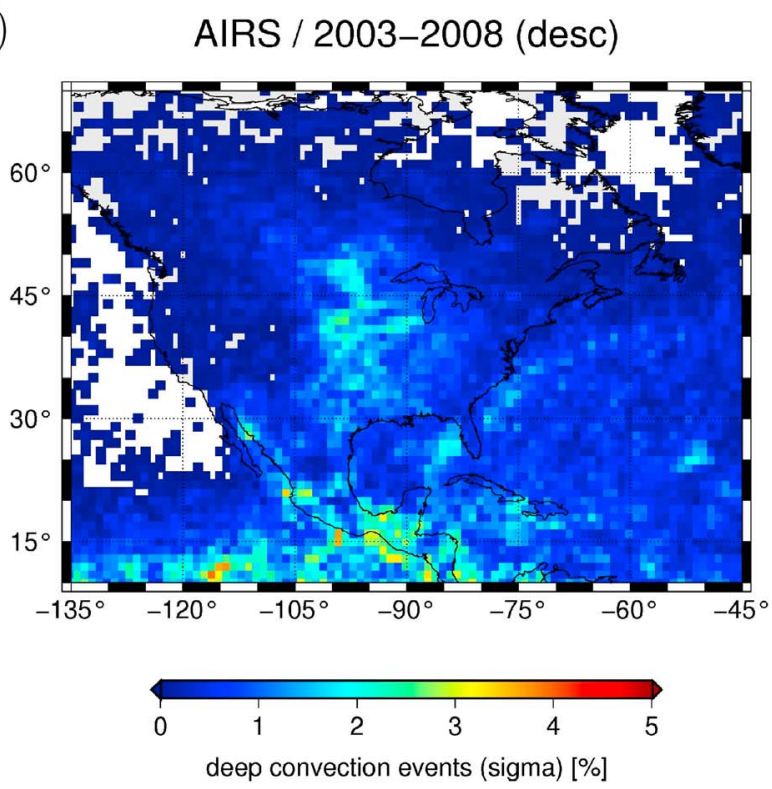

d)

AIRS / 2003-2008 (asc)

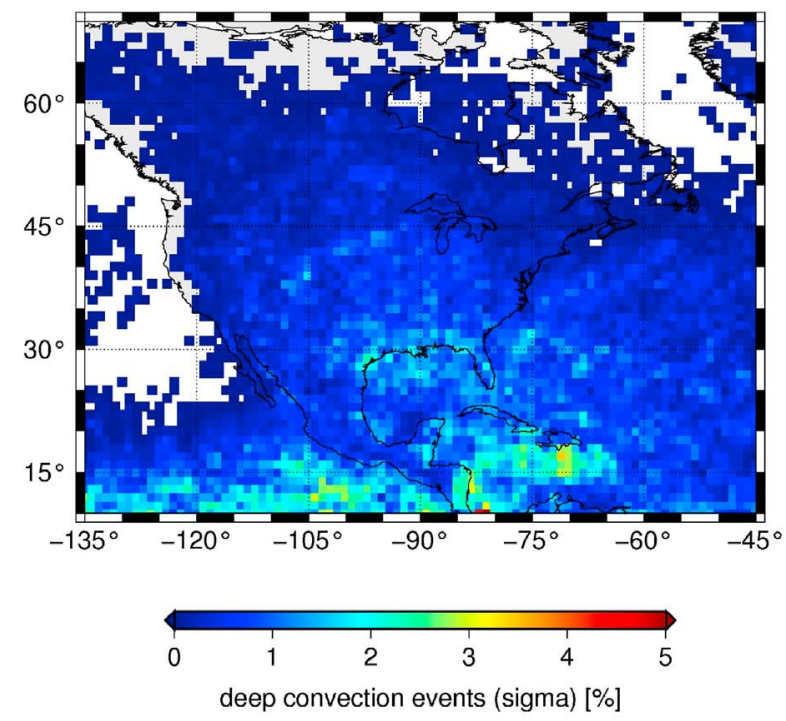

Figure 2. Occurrence frequency of deep convection events over the North American continent as obtained from AIRS observations. Analysis covers the months May to August during the years 2003-2008. Data are separately analyzed for (a, b) 0130 LT (descending orbits) and (c, d) 1330 LT (ascending orbits). Shown are mean (Figures $2 \mathrm{a}$ and $2 \mathrm{c}$ ) and standard deviation (Figures $2 \mathrm{~b}$ and $2 \mathrm{~d}$ ) of the seasonal occurrence frequency.

that the mean brightness temperature will not be influenced by clouds.

[21] The $4.3 \mu \mathrm{m}$ brightness temperatures show a pronounced scan angle-dependent brightening effect, i.e., increased radiance toward the sublimb, which is due to the elongated atmospheric paths in the sublimb direction compared with nadir. They also show a variable background due to planetary wave activity. Before gravity waves can be detected from the radiance measurements a detrending procedure needs to be applied. To detrend the data we subtract a fourth-order polynomial fit in the across-track direction from the brightness temperatures of each scan. A polynomial degree of less than 4 will not be sufficient to remove the scan angle brightening effect and other background terms completely. By construction this detrending procedure will completely remove any plane-parallel wave components oriented in the along-track direction.

[22] Gravity waves due to deep convection can be identified from AIRS data by eye easily based on their characteristic circular shaped wave front patterns (e.g., Figure 1a). However, due to the large amount of AIRS observations an automated procedure needs to be defined to determine the occurrence frequency of gravity waves on a statistical basis. For this purpose we apply a variance filter to the detrended mean $4.3 \mu \mathrm{m}$ brightness temperature perturbations. For each footprint the variance $\sigma^{2}$ of the brightness temperature per- 


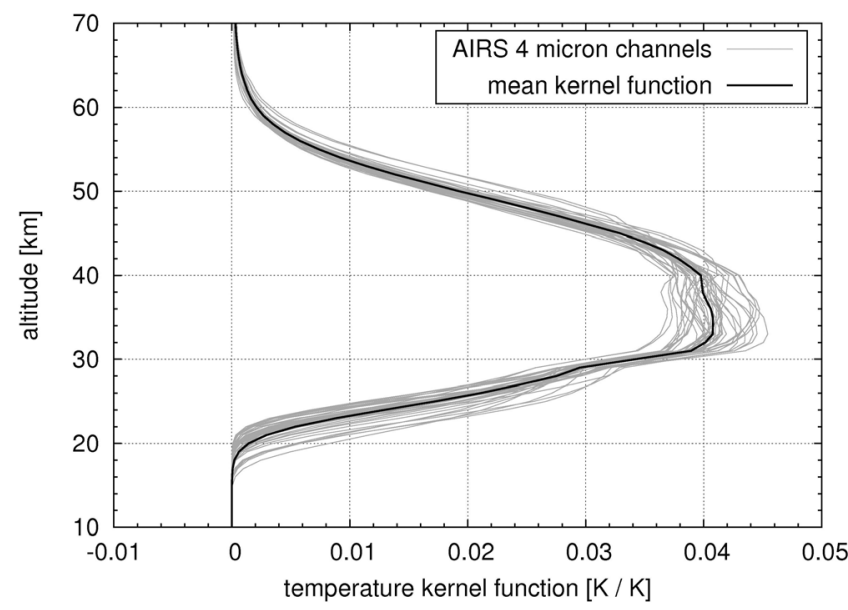

Figure 3. Temperature kernel functions for 42 AIRS channels $\left(2322.6-2366.9 \mathrm{~cm}^{-1}\right)$ in the $4.3 \mu \mathrm{m} \mathrm{CO}_{2}$ band. The thick black curve shows the mean kernel function from all individual channels. Computations are carried out for midlatitude atmospheric conditions [Remedios et al., 2007] and the nadir viewing direction.

turbations of all footprints within a distance $r \leq r_{\max }$ is calculated. If the variance exceeds a minimum threshold, $\sigma^{2} \geq$ $\sigma_{T}^{2}$, we assume a stratospheric gravity wave to be present in the corresponding footprint. The values of $r_{\max }$ and $\sigma_{T}^{2}$ are both important tuning parameters of the variance filter to which the detection algorithm reacts sensitively.

[23] The minimum variance threshold $\sigma_{T}^{2}=0.05 \mathrm{~K}^{2}$ was selected based on a comparison with measurement noise. The noise equivalent delta temperature for a $250 \mathrm{~K}$ brightness temperature scene for the 2322.6 to $2366.9 \mathrm{~cm}^{-1}$ AIRS channels is $0.36 \mathrm{~K}$ [Pagano et al., 2003]. If it is assumed that all channels are sensitive to the same part of the temperature profile and all measurements are uncorrelated the expected variance of the mean brightness temperature due to noise is $\sigma_{N}^{2}=(0.36 \mathrm{~K} / \sqrt{42})^{2} \approx 0.003 \mathrm{~K}^{2}$. However, as the AIRS channels averaged here do not have exactly the same weighting functions, $\sigma_{N}^{2}$ underestimates the real background level to some degree. Therefore we additionally estimate the background level from measurements, based on all observations made in June 2005. A variance of $\sigma_{M}^{2} \approx 0.0043 \mathrm{~K}^{2}$ is found. The selected threshold $\sigma_{T}^{2}=0.05 \mathrm{~K}^{2}$ is ten times higher than $\sigma_{N}^{2}$ or $\sigma_{M}^{2}$, i.e., detection is extremely unlikely to be obscured by measurement noise.

[24] Since we are interested in good spatial localization of the detection results the detection area, or $r_{\max }$, should be as small as possible. On the other hand, $r_{\max }$ should not be made too small in order to have a sufficient number of AIRS footprints within the detection area to allow for a statistically significant estimation of variance. Based on a test series with radius values in the range from 50 to $500 \mathrm{~km}$, we conclude that $r_{\text {max }}=100 \mathrm{~km}$ is best suited for the detection of the convective wave patterns we are interested in. For $r_{\max }=$ $100 \mathrm{~km}$ the individual variances are based on 50 to 130 AIRS footprints each, with the maximum number of footprints being obtained in the nadir viewing direction.

[25] The detection scheme for gravity waves presented here can be applied to the AIRS measurements without significant computational effort. The parameters for detrending and variance filtering are optimized empirically to obtain satisfying detection results. In addition, we made an effort to provide a more quantitative characterization of the sensitivity of the detection method (see Appendix A). We conclude that the detection procedure is sensitive to horizontal wavelengths (in the across-track direction) from 50 to $1000 \mathrm{~km}$. It is sensitive to vertical wavelengths of $15 \mathrm{~km}$ or longer. The method is sensitive to the height range from 20 to $65 \mathrm{~km}$, most sensitive for altitudes from 30 to $40 \mathrm{~km}$.

\subsection{Occurrence Frequency of Gravity Waves}

[26] To determine the occurrence frequency of stratospheric gravity waves from AIRS observations we apply the detection algorithm described previously (section 4.2) and the same gridding of measurements as used for the analysis of deep convection (section 3.3). Again, the analysis covers the North American continent and the time period from 1 May to 31 August during the years 2003 to 2008. Mean values and standard deviations of the yearly seasonal gravity wave occurrence frequency are presented in Figure 4.

[27] While the occurrence frequencies for daytime AIRS observations are rather low (mostly below 1 to $2 \%$ ) and do not show prominent features, the nighttime observations reveal two distinct regions where values are significantly increased: Occurrence frequencies become as high as $(8 \pm 3) \%$ over the North American Great Plains. In this region the spatial distributions of gravity waves and deep convection are clearly associated (compare Figure 2). A second pattern of enhanced gravity wave activity is found over the Atlantic Ocean, east of Florida and Cuba. In this region the occurrence frequency is $(6 \pm 2) \%$.

[28] Interestingly, no significant gravity wave activity is observed by AIRS at tropical latitudes even though deep convection activity is highest in these areas. Although we expect a significant amount of gravity waves emitted by the convective sources at low latitudes, we explain the lack of signal by the fact that the low-latitude waves typically have short vertical wavelengths which cannot be observed by AIRS (see sections 4.1 and 4.2), which is very likely related to the refraction effect of latitudinally varying background winds on the wave vertical wavelength, see equation (2). Conversely, at midlatitudes strong background winds lead to propagation of waves with long vertical wavelengths which can be observed by the AIRS instrument.

[29] To discuss gravity wave propagation in more detail we briefly repeat two important equations from linear theory for perturbations to a horizontally uniform background state [e.g., Fritts and Alexander, 2003]. For gravity waves with midrange intrinsic frequencies the vertical group velocity $c_{g z}$ is related to the vertical wavelength $\lambda_{z}$ and horizontal wavelength $\lambda_{h}$,

$$
c_{g z}=\frac{\lambda_{z}^{2} N}{2 \pi \lambda_{h}}
$$

where $N$ denotes the buoyancy frequency. Furthermore, the vertical wavelength is related to horizontal wind speed $u$ and horizontal group velocity $c_{g h}$,

$$
\lambda_{z}=\frac{2 \pi\left(c_{g h}-u\right)}{N} .
$$


a)
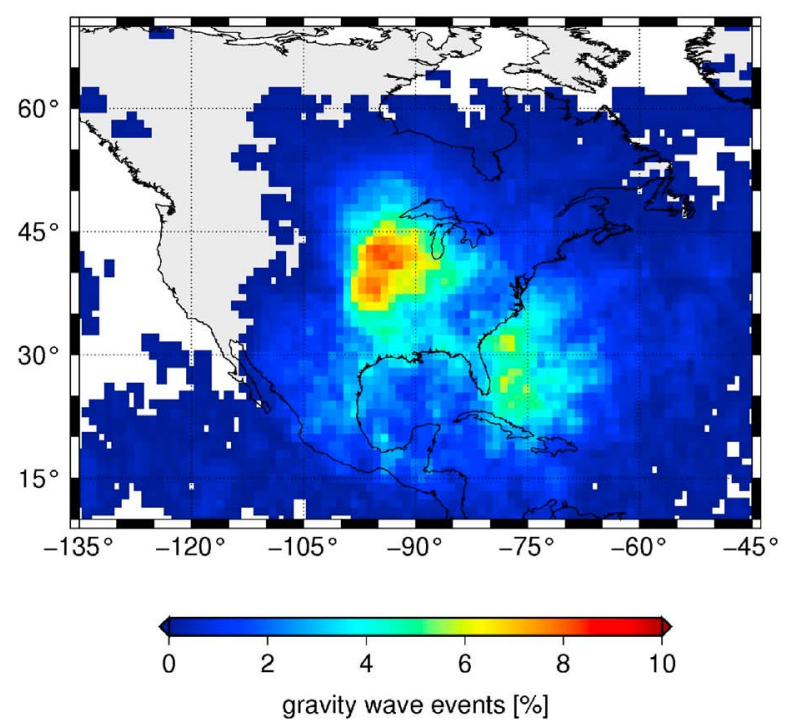

c)

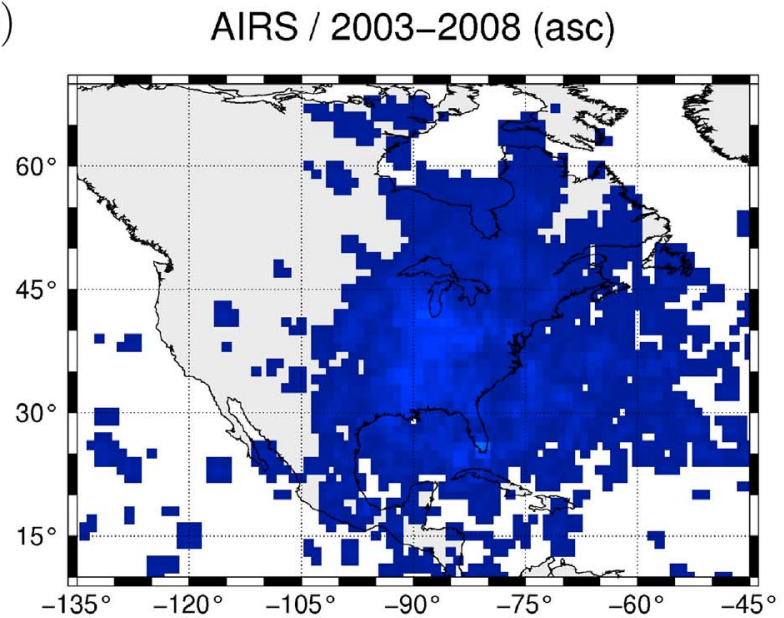

b) AIRS / 2003-2008 (desc)

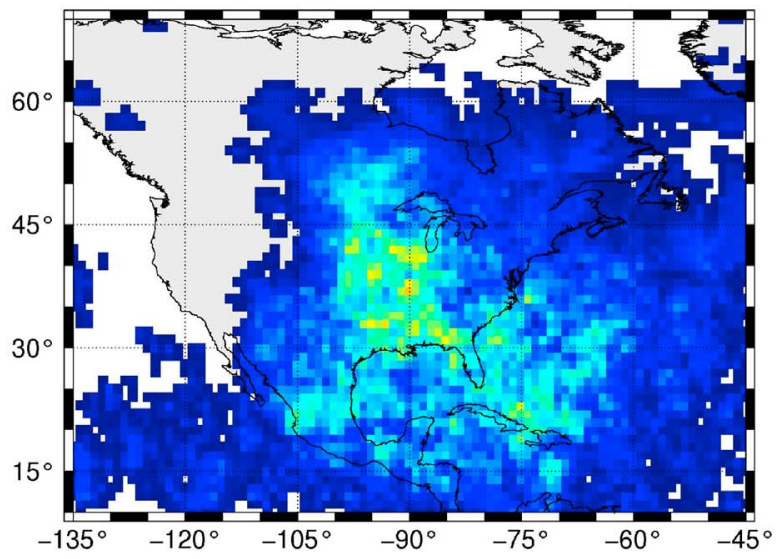

d)

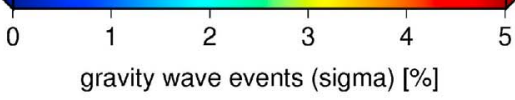

d) AIRS / 2003-2008 (asc)

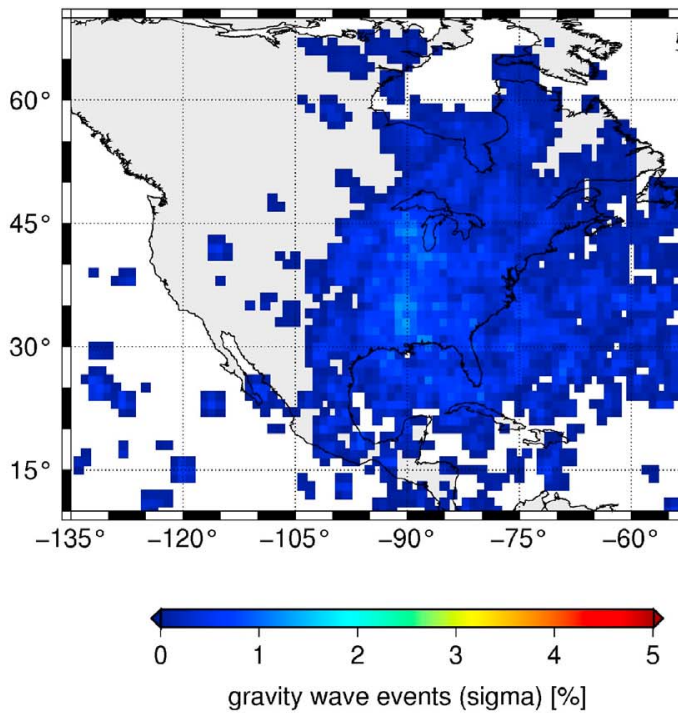

Figure 4. Occurrence frequency of gravity waves over the North American continent as observed by the AIRS instrument. Analysis covers the months May to August during the years 2003-2008. Data are separately analyzed for (a, b) $0130 \mathrm{LT}$ (descending orbits) and (c, d) $1330 \mathrm{LT}$ (ascending orbits). Shown are mean (Figures $4 \mathrm{a}$ and $4 \mathrm{c}$ ) and standard deviation (Figures $4 \mathrm{~b}$ and $4 \mathrm{~d}$ ) of seasonal occurrence frequency.

The midfrequency approximation is less appropriate for quantitative analysis but provides an intuitive view of gravity wave properties and their relationship to background wind and stability.

[30] The method presented in section 4.2 is able to detect gravity waves within a broad range of horizontal wavelengths, i.e., about 50 to $1000 \mathrm{~km}$. With respect to the vertical direction detection is limited to $15 \mathrm{~km}$ vertical wavelength or longer. Equation (1) indicates that gravity waves with long vertical wavelengths and short horizontal wavelengths will propagate fast through the stratosphere. For example, a gravity wave with $15 \mathrm{~km}$ vertical wavelength and $100 \mathrm{~km}$ horizontal wavelength will have a vertical group velocity of
$7.2 \mathrm{~m} / \mathrm{s}$. It will propagate through the stratosphere within $1.2 \mathrm{~h}$. If the horizontal wavelength is increased to $1000 \mathrm{~km}$ the propagation time is increased to $12 \mathrm{~h}$. If the vertical wavelength is increased to $40 \mathrm{~km}$ the propagation time is reduced to $10 \mathrm{~min}$. If vertical and horizontal wavelengths are both increased the propagation time becomes $1.6 \mathrm{~h}$. Equation (2) indicates that long vertical wavelengths require strong background winds. If the horizontal group velocity is zero, vertical wavelengths of $15 \mathrm{~km}$ or $40 \mathrm{~km}$ correspond to wind velocities of $50 \mathrm{~m} / \mathrm{s}$ and $130 \mathrm{~m} / \mathrm{s}$, respectively.

[31] Based on these arguments we conclude that the enhanced gravity wave activity during nighttime in the North American Midwest is directly linked to the simultaneous 
presence of mesoscale convective systems. Gravity waves with long vertical wavelengths propagate into the stratosphere within only 1 to $2 \mathrm{~h}$ and can be detected by AIRS. The reduced gravity wave activity during daytime is related to waves with shorter vertical wavelengths and longer horizontal wavelengths. These waves require about half a day to propagate into the stratosphere, i.e., were already triggered at an earlier stage. A visual inspection of daily $4.3 \mu \mathrm{m}$ brightness temperature perturbation maps, like the one presented in Figure 1, reveals that the daytime gravity waves typically have much longer horizontal wavelengths than the nighttime gravity waves.

\section{Joint Observations of Deep Convection and Gravity Waves}

\subsection{Spatial Correlations of Observations}

[32] In order to estimate the fraction of convective waves, we analyze for each gravity wave event, whether a deep convection event is also detectable in the surrounding AIRS footprints. The fraction of convective waves is determined with respect to the total number of gravity wave observations as presented in section 4.3. Since convective waves do not necessarily propagate only in the vertical direction we use a search radius of $r_{s}=500 \mathrm{~km}$ for this analysis. A large value for $r_{s}$ ensures that even convective waves with very strong horizontal propagation may be tracked back to their origin. The analysis is restricted to cases of nearly simultaneous presence of gravity waves and deep convection, i.e., the difference of the corresponding measurement times is limited to be less than $6 \mathrm{~min}$. We also restrict this analysis to grid boxes for which gravity waves are observed at least in 3 years. Otherwise the total number of observed gravity waves would be too low to reasonably estimate the fraction of convective waves.

[33] The estimated fraction of convective waves is shown as the color scale in Figures $5 \mathrm{a}$ and $5 \mathrm{~b}$ and contours reproduce gravity wave occurrence frequencies from Figures $4 \mathrm{a}$ and $4 \mathrm{~b}$ for reference. The fraction of convective waves approaches values over $95 \%$ in the Midwest region during nighttime (Figure 5a). Comparably high fractions of convective waves are found in the area of the North American Monsoon (Mexico, California), although the observed gravity wave activity itself is much lower. We also find high fraction of convective waves (up to $80 \%$ ) for the area of enhanced gravity wave activity over the Atlantic Ocean in Figure 5a. For the daytime observations (Figure $5 b$ ) the Midwest pattern is much less pronounced since convection is significantly reduced. High fractions of convective waves are found over the Mexican Gulf and its U.S. coasts as well as the Atlantic Ocean near Florida and Cuba.

[34] For the purpose of validation of gravity wave parameterization schemes which take into account convective sources we also try to answer the question of how many deep convection events generate gravity waves that can be observed by AIRS. Similar to the estimation of the fraction of convective waves, we determine for each detected deep convection event whether a gravity wave can be identified in the surrounding AIRS footprints. Again, a search radius of $500 \mathrm{~km}$ is applied. The results of this analysis are presented in Figures $5 \mathrm{c}$ and $5 \mathrm{~d}$ for night- and daytime measurements, respectively. The color scale shows the fraction of convective clouds associated with a wave event, and the contours reproduce the deep cloud occurrence frequencies from Figures $2 \mathrm{a}$ and $2 \mathrm{~b}$ for reference. Comparing daytime and nighttime, the AIRS data show a significantly enhanced frequency of gravity wave emitting deep convection events during the nighttime. In a broad region in the Midwest as well as over the Mexican Gulf and the Atlantic Ocean near Florida and Cuba the fraction of gravity wave emitting events typically exceeds the $50 \%$ level at night. Maximum fractions (up to $90 \%$ ) are found south and west of the Great Lakes. In the same region maximum fractions (up to $60 \%$ ) are also found in the AIRS daytime observations, while for the Mexican Gulf and Atlantic Ocean the fractions are significantly reduced (below 10\%). The good correspondence of the fraction of convective waves and the fraction of wave emitting convection events in the Midwest lead to the conclusion that this region is well suited to study the characteristics of convective waves at midlatitudes and to apply AIRS measurements made here (particularly during the nighttime) to validate gravity wave parameterization schemes.

\subsection{Temporal Correlations of Observations}

[35] To analyze the temporal correlations of deep convection and gravity wave activity we determine time series on a daily basis for two regions. The "broad Midwest region" is defined as the area where the occurrence frequency for convective waves (section 5.1) exceeds the $1 \%$ level. It extends from 110 to $78^{\circ} \mathrm{W}$ and 16 to $54^{\circ} \mathrm{N}$. Further, a "core region" is defined as the area where the occurrence frequency exceeds the $5 \%$ level. It extends from 98 to $88^{\circ} \mathrm{W}$ and 36 to $46^{\circ} \mathrm{N}$. The time series of nighttime AIRS observations for the core region are shown in Figure 6. The strongest correlations between deep convection and gravity waves are observed for these particular time series. This is remarkable since the most prominent feature of both time series is the large interseasonal and intraseasonal variability.

[36] A visual inspection of the time series indicates that deep convection and gravity wave activity are statistically associated. For a quantitative analysis we determine the Spearman rank-order correlation coefficient and the Pearson linear correlation coefficient. The Spearman correlation coefficient $\rho_{S}$ is used to detect nonparametric correlations, i.e., will be sensitive to almost any kind of correlation present in the data. It is more robust than linear correlation and more resistant to data deficiencies. The Pearson correlation coefficient $\rho_{P}$ provides a good measure for the strength of linear correlation in the data, but it is generally a rather poor statistic for deciding whether an observed correlation is significant. For mathematical definitions and further discussion see Press et al. [2002]. Please note that the analysis presented here is restricted to direct temporal correlations, any diurnal or semidiurnal lags are not taken into account.

[37] For the AIRS nighttime observations in the core region we find that $\rho_{S}$ varies from 0.49 to 0.7 during the individual years (Figure 6). All significance values are below $10^{-8}$, indicating that the observed nonparametric correlations are highly significant. The yearly values of $\rho_{P}$ vary from 0.34 to 0.75 , indicating that there is also a medium to high level of linear correlation. The full time series have correlation coefficients $\rho_{S}=0.56$ and $\rho_{P}=0.54$. For the daytime observations, correlations are weaker and less linear, i.e., $\rho_{S}=0.33$ and $\rho_{P}=$ 0.29 . If we extend the analysis to the broad Midwest region we estimate $\rho_{S}=0.48$ and $\rho_{P}=0.50$ for the nighttime 
a)

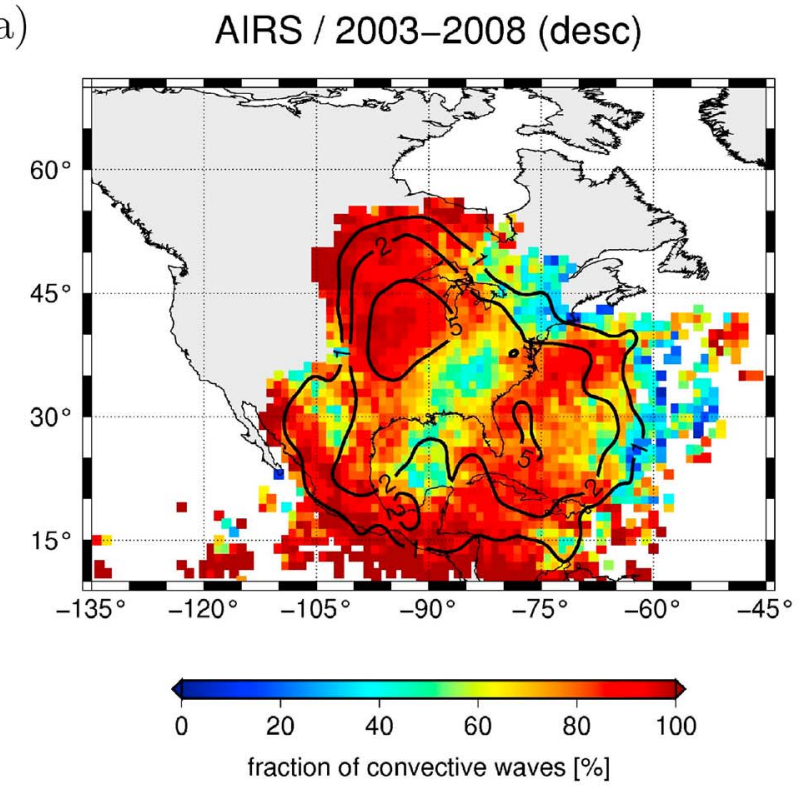

c)

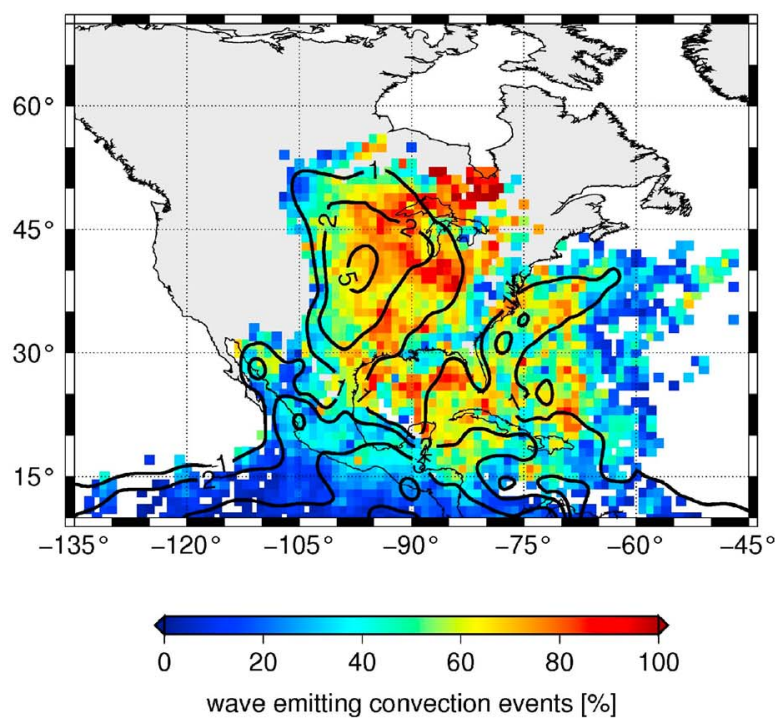

b)

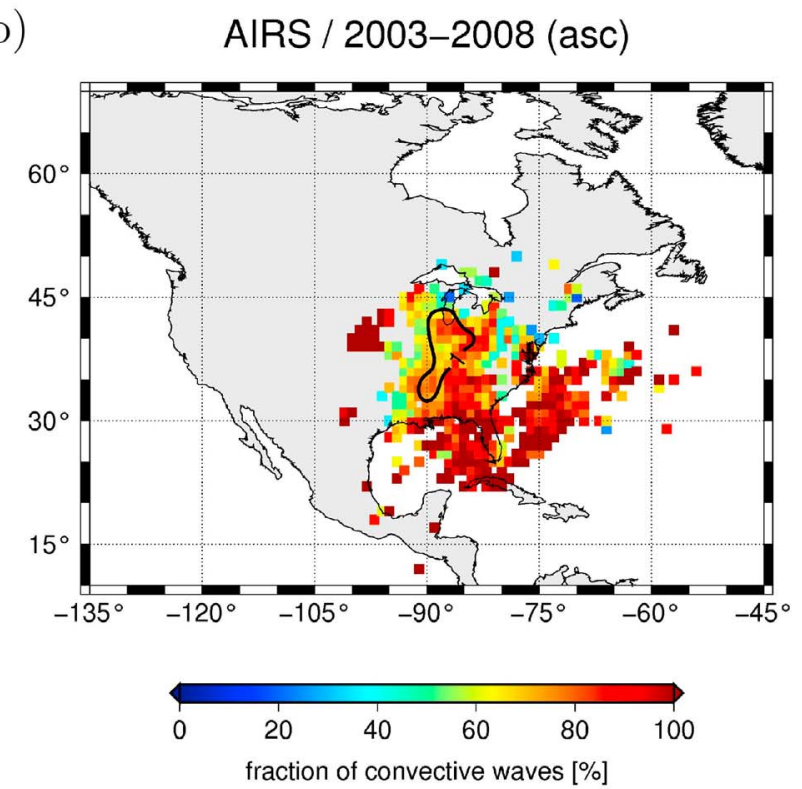

d)

AIRS / 2003-2008 (asc)

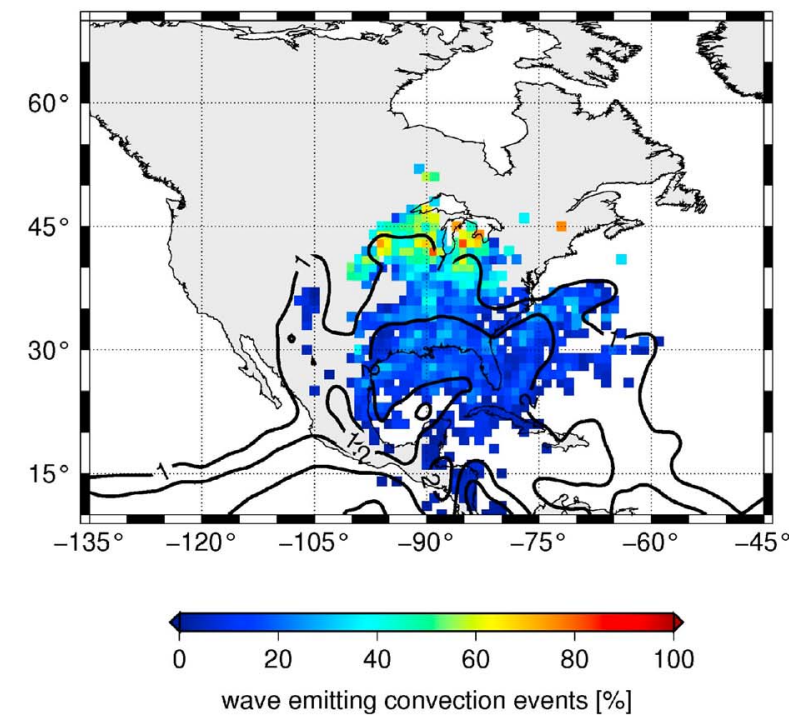

Figure 5. Fractions of $(a, b)$ convectively generated gravity waves and $(c, d)$ wave emitting convection events. Analysis covers the months May to August during the years 2003-2008. Data are separately analyzed for $0130 \mathrm{LT}$ (descending orbits) (Figures 5a and 5c) and $1330 \mathrm{LT}$ (ascending orbits) (Figures 5b and 5d). Estimates are based on the nearly simultaneous detection of deep convection and gravity waves within AIRS footprints separated by less than $500 \mathrm{~km}$ distance and 6 min time. Black contour lines indicate the $1 \%, 2 \%$, and $5 \%$ level of gravity wave occurrence frequency (Figures $5 \mathrm{a}$ and $5 \mathrm{~b}$ ) and deep convection occurrence frequency (Figures $5 \mathrm{c}$ and $5 \mathrm{~d}$ ).

observations and $\rho_{S}=0.31$ and $\rho_{P}=0.12$ for the daytime observations. Strong correlations for the broad Midwest region are still found during the nighttime but they are degraded further during the daytime.

[38] We also applied the technique of correlation analysis to infer the statistical association with other measured quantities. Assuming that minimum values of brightness temperatures may provide a good proxy for the strength of deep convection (compare Figure 6), we analyze the correlations between the time series of convective gravity waves and the daily minimum brightness temperature in the particular region. For the core region we find $\rho_{S}=-0.61$ and $\rho_{P}=-0.51$ for the nighttime and $\rho_{S}=-0.58$ and $\rho_{P}=-0.55$ for the daytime. For the broad Midwest region we find $\rho_{S}=-0.57$ and $\rho_{P}=-0.44$ for the nighttime and $\rho_{S}=-0.45$ and $\rho_{P}=$ -0.29 for the daytime. This indicates that the minimum brightness temperatures are indeed a slightly better proxy for gravity wave activity than the daily number of observations of deep convective events, especially for the daytime observations. In addition, we analyzed the correlations between the 

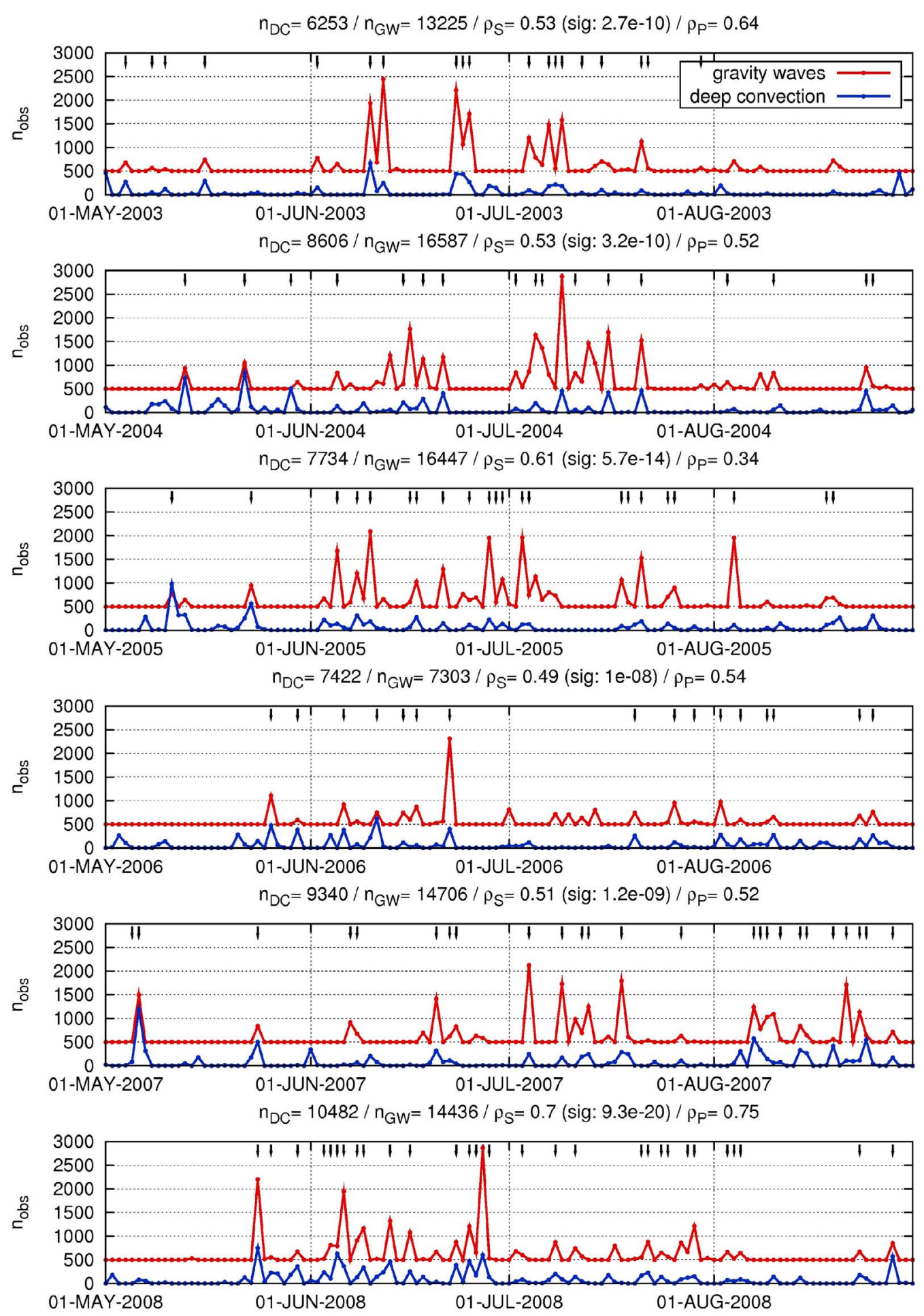

Figure 6. Time series of daily numbers $n_{o b s}$ of nighttime AIRS observations of gravity waves (red curve, plotted with an offset of 500) and deep convection events (blue curve, no offset) within a "core region" in the Midwest $\left(36^{\circ} \mathrm{N}-46^{\circ} \mathrm{N}, 88^{\circ} \mathrm{W}-98^{\circ} \mathrm{W}\right)$. Small arrows at the top of the plots indicate days with strong deep convection events $(8.1 \mu \mathrm{m}$ brightness temperatures below $210 \mathrm{~K})$. Plot titles list total numbers $n_{D C}$ and $n_{G W}$ of deep convection and gravity wave events as well as the correlation coefficients $\rho_{S}$ and $\rho_{P}$ by Spearman and Pearson for each year. 
time series of convective gravity waves (section 5.1) and all gravity waves. We find that $\rho_{S}$ varies from 0.88 to 0.95 and $\rho_{P}$ varies from 0.88 to 0.96 . This again confirms that nearly all observed gravity waves in the core region as well as the broad Midwest region arise due to deep convection.

\section{Conclusions}

[39] In this paper we present two algorithms to detect deep convective clouds and stratospheric gravity waves in AIRS radiance measurements. A detailed study of the sensitivity of the new gravity wave detection algorithm is presented. By averaging radiance measurements and reducing noise we were able to optimize the algorithm to detect even plane waves with vertical wavelengths as short as $15 \mathrm{~km}$, which is significantly shorter than the width of the $4.3 \mu \mathrm{m}$ weighting functions of the nadir sounding AIRS instrument.

[40] The detection algorithms are applied to determine the occurrence frequencies of deep convection and gravity waves during the North American thunderstorm season during the years 2003 to 2008. Based on correlation analyses we are able to estimate the fraction of convective waves and the fraction of wave emitting convection events. In the AIRS nighttime measurements a "core region" over the Great Plains (36 to $46^{\circ} \mathrm{N}, 98$ to $88^{\circ} \mathrm{W}$ ) was identified, in which seasonal mean occurrence frequencies get as high as $6 \%$ for deep convection and $8 \%$ for gravity waves. In this region gravity waves are very commonly seen by AIRS wherever deep convection occurs, and the estimated fraction of convective waves exceeds $95 \%$.

[41] While proximity to convection is not proof of the source, other sources are unlikely. Stationary mountain waves cannot propagate into easterly summer stratosphere winds. Jet imbalance is an important gravity wave source [Uccellini and Koch, 1987], however waves identified in the stratosphere emanating from regions of jet imbalance have shorter vertical wavelength than can be observed with AIRS [Guest et al., 2000; Plougonven and Snyder, 2005, 2007] or have occurred in winter conditions [O'Sullivan and Dunkerton, 1995; Plougonven et al., 2003; Zhang, 2004; $W u$ and Zhang, 2004; Limpasuvan et al., 2007]. The concentric semicircular arc patterns we observe in the summertime AIRS observations over North America are strikingly similar to observations and models of waves generated by convection.

[42] The tight correlations between deep convection and gravity waves in the North American Midwest indicate that this area is well suited to investigate the individual characteristics of convective waves at midlatitudes. We envisage a detailed study of both the horizontal and vertical structure of these waves based on a high spatial resolution temperature dataset obtained from AIRS radiance measurements with a retrieval scheme presented by Hoffmann and Alexander [2009]. Considering the large amount of AIRS measurements and the computational effort for the retrievals (about $8 \mathrm{~h}$ of CPU time per AIRS granule on a standard workstation), the gravity wave detection algorithm presented here is a very useful tool to preselect individual AIRS granules, showing convective waves, to be processed and analyzed in more detail.

[43] The occurrence frequency statistics of deep convective clouds and gravity waves presented in this paper are likely to be a very valuable data set for the purpose of validation of gravity wave parameterization schemes used in general circulation models. The parameterization of Beres et al. [2004, 2005], for example, which shows significant impacts on global circulation, is based on convective wave source spectra that remain unvalidated. In particular, the waves observed by AIRS tend to have long vertical wavelengths and short horizontal wavelengths, and via (1) and (2), also fast group velocities and horizontal phase speeds. This type of wave is difficult to detect in other types of observations such as limb profiling satellites and radiosondes. The data sets presented here as well as the on-going analysis of wave properties will likely help to provide the much needed empirical evidence for theoretical considerations upon which the parameterization scheme is built.

\section{Appendix A: Sensitivity of the Gravity Wave Detection Algorithm}

[44] Even though the gravity wave detection algorithm described in section 4.2 is technically simple, it takes some effort to derive a proper characterization of its sensitivity. This can be done, though, by applying a radiative transfer model which allows simulation of AIRS radiance measurements for a given temperature field. By applying the detrending procedure and the variance filter described in section 4.2 to the simulated measurements it can be assessed if the detection algorithm will be able to detect any given temperature perturbations imposed on the background field or not.

[45] Here we summarize the results of a sensitivity study of the detection algorithm based on idealized assumptions. For this study we apply the Juelich Rapid Spectral Simulation Code (JURASSIC) as a forward model to simulate AIRS radiance measurements [Hoffmann, 2006; Hoffmann and Alexander, 2009]. The gravity wave perturbations imposed on the temperature background field are simulated as a planeparallel wave,

$$
\Delta T=T(z) \sin \left(\frac{2 \pi}{\lambda_{x}} x+\frac{2 \pi}{\lambda_{y}} y+\frac{2 \pi}{\lambda_{z}} z+\phi\right),
$$

which seems to be a reasonable assumption at least for small detection areas (as specified by $r_{\max }$ ). In equation (A1) the wave amplitude is denoted $T(z), x$ is the along-track distance, $y$ is the across-track distance, and $z$ is height. The wavelengths are denoted $\lambda_{x}, \lambda_{y}$, and $\lambda_{z}$, respectively. The phase of the wave is denoted $\phi$. Following linear wave theory, $T(z)$ grows exponentially with height [e.g., Fritts and Alexander, 2003],

$$
T(z)=T_{0} \exp \left(\frac{z-z_{0}}{2 H}\right)
$$

where $H \approx 7 \mathrm{~km}$ denotes the stratospheric scale height. In our simulation we set $T_{0}=5 \mathrm{~km}$ as a representative value, based on a climatological data set for gravity wave activity [Preusse et al., 2009]. Since any particular wave may have an amplitude differing from this value it should be pointed out that the results presented here vary linearly with $T_{0}$ to a large extent. 


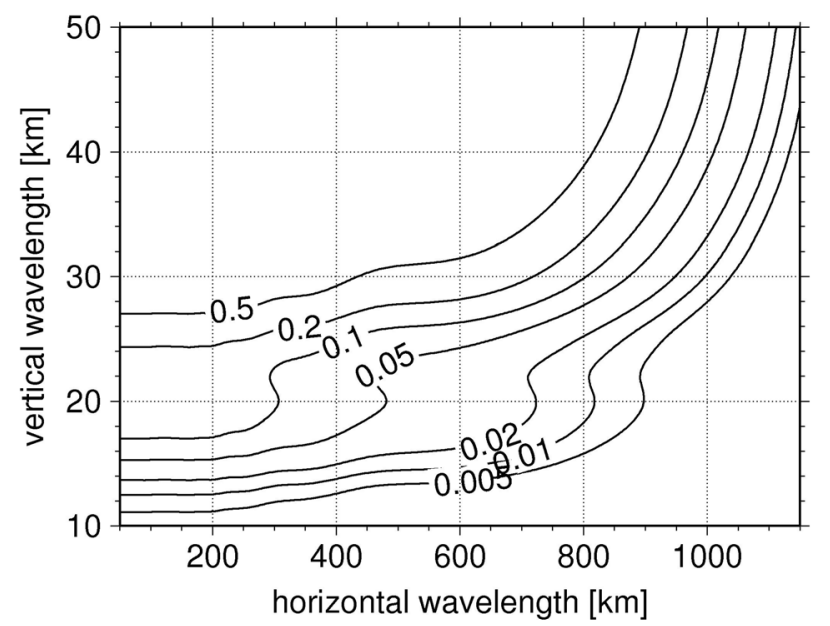

Figure A1. Sensitivity of the gravity wave detection algorithm discussed in section 4.2. Contour lines indicate the dependence of detrended $4.3 \mu \mathrm{m}$ brightness temperature mean variances in $\mathrm{K}^{2}$ for a plane wave on different horizontal and vertical wavelengths.

At upper altitudes the wave amplitude will be limited by saturation processes [e.g., Preusse et al., 2008],

$$
T(z) \leq T_{s a t}=\frac{\lambda_{z}}{2 \pi} \frac{T_{b g}}{g} N^{2}
$$

where $T_{b g} \approx 250 \mathrm{~K}$ denotes the background temperature, $g \approx$ $9.81 \mathrm{~m} / \mathrm{s}^{2}$ the acceleration due to gravity, and $N \approx 0.02 / \mathrm{s}$ the buoyancy frequency.

[46] As discussed in section 4.2 the detection algorithm will not be able to detect any gravity wave components in the along-track direction because these are removed by the detrending procedure. For this study we assume that the wave fronts are oriented parallel to the across-track direction to obtain the maximum response. Figure A1 shows the mean variance of simulated AIRS $4.3 \mu \mathrm{m}$ brightness temperatures obtained for different horizontal and vertical wavelengths. For our nominal variance filter setup $\left(\sigma_{T}^{2}=0.05 \mathrm{~K}\right.$ and $r_{\max }=$ $100 \mathrm{~km}$ ) the detection algorithm will be sensitive to vertical wavelengths longer than $15 \mathrm{~km}$ and horizontal wavelengths shorter than $1050 \mathrm{~km}$. However, the sensitivity to short vertical wavelengths gradually degrades for long horizontal wavelengths.

[47] For rather long horizontal wavelengths the sensitivity of the variance filter depends on the wave phase $\phi$. The longest horizontal wavelength that can be detected varies from 750 to $1100 \mathrm{~km}$ with $\phi$, depending on the particular instantaneous phase of the wave within the detection area. Waves with very long horizontal wavelengths will not be detected "as a whole" in all AIRS footprints. Instead, positive detection will only occur at AIRS footprints which are located near zero crossings of the wave. For Figure A1, we decided to show the mean variance, obtained when varying $\phi$, as being most representative.

[48] For long horizontal wavelengths the sensitivity of the detection algorithm also depends on the size of the detection area as specified by $r_{\max }$. Increasing $r_{\max }$ from 100 to $500 \mathrm{~km}$ increases the longest detectable horizontal wavelength from 1050 to $1400 \mathrm{~km}$. Note that for large $r_{\max }$ the detection sensitivity will be limited by the detrending procedure and the AIRS scan width rather than the variance filter. Since we are generally interested in a local detection, we try to keep the radius $r_{\max }$ of the detection area small.

[49] For short horizontal wavelengths the sensitivity of the variance filter does not depend on either $\phi$ or $r_{\max }$ at all. In this case the sensitivity is entirely determined by the $4.3 \mu \mathrm{m}$ temperature kernel functions presented in Figure 3. It should be stressed that the sensitivity to rather short vertical wavelengths (down to $15 \mathrm{~km}$ ) compared to the broad FWHM of the kernel functions (about $25 \mathrm{~km}$ ) is mainly achieved by reducing the noise level by means of averaging of AIRS radiance channels. If just one AIRS channel would be selected for detection the variance threshold $\sigma_{T}$ would need to be increased to $0.2-0.5 \mathrm{~K}^{2}$ to compensate for higher noise. As illustrated in Figure A1 the shortest vertical wavelength that could be detected would increase to $24-27 \mathrm{~km}$ in this case.

[50] Acknowledgments. Support for this work was provided by the NASA program Earth System Science Research using Data and Products from TERRA, AQUA, and ACRIM Satellites, contract NNH06ZDA001N 06-EOS/06-0203 and NSF Physical and Dynamical Meteorology Program 0632378. We thank Manfred Ern and Peter Preusse, both at Forschungszentrum Jülich, Germany, for suggestions and comments related to this study. We thank Duy-Viet Do, Forschungszentrum Jülich, Germany, for technical support.

\section{References}

Ahijevych, D. A., C. A. Davis, R. E. Carbone, and J. D. Tuttle (2004), Initiation of precipitation episodes relative to elevated terrain, J. Atmos. Sci., 61(22), 2763-2769.

Alexander, M. J., and L. Pfister (1995), Gravity wave momentum flux in the lower stratosphere over convection, Geophys. Res. Lett., 22(15), 2029-2032, doi:10.1029/95GL01984.

Alexander, M. J., and K. H. Rosenlof (1996), Nonstationary gravity wave forcing of the stratospheric zonal mean wind, J. Geophys. Res., 101(D18), 23,465-23,474, doi:10.1029/96JD02197.

Alexander, M. J., J. H. Beres, and L. Pfister (2000), Tropical stratospheric gravity wave activity and relationships to clouds, J. Geophys. Res., 105(D17), 22,299-22,309, doi:10.1029/2000JD900326.

Alexander, M. J., et al. (2008), Global estimates of gravity wave momentum flux from High Resolution Dynamics Limb Sounder (HIRDLS) observations, J. Geophys. Res., 113, D15S18, doi:10.1029/2007JD008807.

Allen, S. J., and R. A. Vincent (1995), Gravity wave activity in the lower atmosphere: Seasonal and latitudinal variations, J. Geophys. Res., 100(D1), 1327-1350, doi:10.1029/94JD02688.

Andrews, D. G., J. R. Holton, and C. B. Leovy (1987), Middle Atmosphere Dynamics, Int. Geophys. Ser., vol. 40, Academic, San Diego, Calif.

Ashley, W. S., T. L. Mote, P. G. Dixon, S. L. Trotter, E. J. Powell, J. D. Durkee, and A. J. Grundstein (2003), Distribution of mesoscale convective complex rainfall in the united states, Mon. Weather. Rev., 131(12), 3003-3017.

Aumann, H. H., D. T. Gregorich, S. L. Gaiser, D. F. Hagan, T. S. Pagano, L. L. Strow, and D. Ting (2000), AIRS level $1 \mathrm{~b}$ algorithm thoretical basis document (ATBD) part 1 (IR), Tech. Rep., NASA. (http://eospso.gsfc. nasa.gov/eos_homepage/for_scientists/atbd)

Aumann, H. H., et al. (2003), AIRS/AMSU/HSB on the Aqua mission: Design, science objective, data products, and processing systems, IEEE Trans. Geosci. Remote Sens., 41, 253-264.

Aumann, H. H., S. Broberg, D. Elliott, S. Gaiser, and D. Gregorich (2006a), Three years of Atmospheric Infrared Sounder radiometric calibration validation using sea surface temperatures, J. Geophys. Res., 111, D16S90, doi:10.1029/2005JD006822.

Aumann, H. H., D. Gregorich, and S. M. DeSouza-Machado (2006b), AIRS observations of deep convective clouds, Proc. SPIE, 6301, 63010J, doi:10.1117/12.681201.

Beres, J. H., M. J. Alexander, and J. R. Holton (2004), A method of specifying the gravity wave spectrum above convection based on latent heating properties and background wind, J. Atmos. Sci., 61(3), 324-337. 
Beres, J. H., R. R. Garcia, B. A. Boville, and F. Sassi (2005), Implementation of a gravity wave source spectrum parameterization dependen on the properties of convection in the Whole Atmosphere Community Climate Model (WACCM), J. Geophys. Res., 110, D10108, doi:10.1029/2004JD005504

Carbone, R. E., J. D. Tuttle, D. A. Ahijevych, and S. B. Trier (2002), Inferences of predictability associated with warm season precipitation episodes, J. Atmos. Sci., 59(13), 2033-2056.

Dewan, E. M., R. H. Picard, R. R. O’Neil, H. A. Gardiner, J. Gibson, J. D. Mill, E. Richards, M. Kendra, and W. O. Gallery (1998), MSX satellite observations of thunderstorm-generated gravity waves in midwave infrared images of the upper stratosphere, Geophys. Res. Lett., 25(7), 939942, doi:10.1029/98GL00640.

Dhaka, S. K., M. K. Yamamoto, Y. Shibagaki, H. Hashiguchi, M. Yamamoto, and S. Fukao (2005), Convection-induced gravity waves observed by the Equatorial Atmosphere Radar $\left(0.20^{\circ} \mathrm{S}, 100.32^{\circ} \mathrm{E}\right)$ in Indonesia, Geophys. Res. Lett., 32, L14820, doi:10.1029/2005GL022907.

Dutta, G., M. C. A. Kumar, P. V. Kumar, M. V. Ratnam, M. Chandrashekar, Y. Shibagaki, M. Salauddin, and H. A. Basha (2009), Characteristics of high-frequency gravity waves generated by tropical deep convection: Case studies, J. Geophys. Res., 114, D18109, doi:10.1029/2008JD011332.

Eckermann, S. D., I. Hirota, and W. K. Hocking (1995), Gravity wave and equatorial wave morphology of the stratosphere derived from long-term rocket soundings, Q. J. R. Meteorol. Soc., 121(521), 149-186.

Ern, M., P. Preusse, M. J. Alexander, and C. D. Warner (2004), Absolute values of gravity wave momentum flux derived from satellite data, J. Geophys. Res., 109, D20103, doi:10.1029/2004JD004752.

Fritts, D. C., and M. J. Alexander (2003), Gravity wave dynamics and effects in the middle atmosphere, Rev. Geophys., 41(1), 1003, doi:10.1029/2001RG000106.

Grimsdell, A. W., M. J. Alexander, P. T. May, and L. Hoffmann (2010), Model study of waves generated by convection with direct validation via satellite, J. Atmos. Sci., 5, 1617-1631.

Guest, F., M. Reeder, C. Marks, and D. Karoly (2000), Inertia-gravity waves observed in the lower stratosphere over macquarie island, J. Atmos. Sci., 57(5), 737-752.

Hamilton, K. (1991), Climatological statistics of stratospheric inertiagravity waves deduced from historical rocketsonde wind and temperature data, J. Geophys. Res., 96(D11), 20,831-20,839, doi:10.1029/ 91JD02188.

Hecht, J. H., et al. (2009), Imaging of atmospheric gravity waves in the stratosphere and upper mesosphere using satellite and ground-based observations over Australia during the TWPICE campaign, J. Geophys. Res., 114, D18123, doi:10.1029/2008JD011259.

Hirota, I. (1984), Climatology of gravity waves in the middle atmosphere, J. Atmos. Terr. Phys., 46(9), 767-773.

Hoffmann, L. (2006), Schnelle Spurengasretrieval für das Satellitenexperiment Envisat MIPAS, Tech. Rep. JUEL-4207, Forsch. Jülich, Jülich, Germany.

Hoffmann, L., and M. J. Alexander (2009), Retrieval of stratospheric temperatures from Atmospheric Infrared Sounder radiance measurements for gravity wave studies, J. Geophys. Res., 114, D07105, doi:10.1029/ 2008JD011241.

Holton, J. R. (1982), The role of gravity wave induced drag and diffusion on the momentum budget of the mesosphere, J. Atmos. Sci., 39(4), 791-799.

Holton, J. R. (1983), The influence of gravity wave breaking on the general circulation of the middle atmosphere, J. Atmos. Sci., 40(10), 2497-2507.

Jiang, J. H., B. Wang, K. Goya, K. Hocke, S. D. Eckermann, J. Ma, D. L. $\mathrm{Wu}$, and W. J. Read (2004), Geographical distribution and interseasonal variability of tropical deep convection: UARS MLS observations and analyses, J. Geophys. Res., 109, D03111, doi:10.1029/2003JD003756.

Kumar, K. K. (2007), VHF radar investigations on the role of mechanical oscillator effect in exciting convectively generated gravity waves, Geophys. Res. Lett., 34, L01803, doi:10.1029/2006GL027404.

Lane, T. P., M. J. Reeder, and T. L. Clark (2001), Numerical modeling of gravity wave generation by deep tropical convection, J. Atmos. Sci., 58(10), 1249-1274.

Larsen, M. F., W. E. Swartz, and R. F. Woodman (1982), Gravity-wave generation by thunderstorms observed with a vertically-pointing $430 \mathrm{MHz}$ radar, Geophys. Res. Lett., 9(5), 571-574, doi:10.1029/ GL009i005p00571.

Limpasuvan, V., D. L. Wu, M. J. Alexander, M. Xue, M. Hu, S. Pawson, and J. R. Perkins (2007), Stratospheric gravity wave simulation over Greenland during 24 January 2005, J. Geophys. Res., 112, D10115, doi:10.1029/2006JD007823.

Maddox, R. A. (1980), Mesoscale convective complexes, Bull. Am. Meteorol. Soc., 75, 811-822.

McLandress, C., M. J. Alexander, and D. L. Wu (2000), Microwave Limb Sounder observations of gravity waves in the stratosphere: A climatology and interpretation, J. Geophys. Res., 105(D9), 11,947-11,967, doi:10.1029/2000JD900097.

Nalli, N. R., et al. (2006), Ship-based measurements for infrared sensor validation during Aerosol and Ocean Science Expedition 2004, J. Geophys. Res., 111, D09S04, doi:10.1029/2005JD006385.

O’Sullivan, D., and T. J. Dunkerton (1995), Generation of inertia-gravity waves in a simulated life cycle of baroclinic instability, J. Atmos. Sci., 52(21), 3695-3716.

Pagano, T. S., H. H. Aumann, D. E. Hagan, and K. Overoye (2003), Prelaunch and in-flight radiometric calibration of the Atmospheric Infrared Sounder (AIRS), IEEE Trans. Geosci. Remote Sens., 41, 265-273.

Parkinson, C. L. (2003), Aqua: An Earth-observing satellite mission to examine water and other climate variables, IEEE Trans. Geosci. Remote Sens., 41, 173-183.

Pfister, L., W. Starr, R. Craig, M. Loewenstein, and M. Legg (1986), Small-scale motions observed by aircraft in the tropical lower stratosphere: Evidence for mixing and its relationship to large-scale flows, J. Atmos. Sci., 43(24), 3210-3225.

Pfister, L., S. Scott, M. Loewenstein, S. Bowen, and M. Legg (1993), Mesoscale disturbances in the tropical stratosphere excited by convection: Observations and effects on the stratospheric momentum budget, J. Atmos. Sci., 50(8), 1058-1075.

Piani, C., D. Durran, M. J. Alexander, and J. R. Holton (2000), A numerical study of three-dimensional gravity waves triggered by deep tropical convection and their role in the dynamics of the QBO, J. Atmos. Sci., 57(22), 3689-3702.

Plougonven, R., and C. Snyder (2005), Gravity waves excited by jets: Propagation versus generation, Geophys. Res. Lett., 32, L18802, doi:10.1029/ 2005GL023730.

Plougonven, R., and C. Snyder (2007), Inertia-gravity waves spontaneously generated by jets and fronts. Part I: Different baroclinic life cycles, J. Atmos. Sci., 64(7), 2502-2520.

Plougonven, R., H. Teitelbaum, and V. Zeitlin (2003), Inertia-gravity wave generation by the tropospheric midlatitude jet as given by the FASTEX radiosoundings, J. Geophys. Res., 108(D21), 4686, doi:10.1029/ 2003JD003535.

Press, W. H., S. A. Teukolsky, W. T. Vetterling, and B. P. Flannery (2002), Numerical Recipes in C: The Art of Scientific Computing, vol. 1, 2nd ed. Cambridge Univ. Press

Preusse, P., and M. Ern (2005), Indication of convectively generated gravity waves observed by CLAES, Adv. Space Res., 35(11), 1987-1991.

Preusse, P., G. Eidmann, S. D. Eckermann, B. Schaeler, R. Spang, and D. Offermann (2001), Indications of convectively generated gravity waves in CRISTA temperatures, Adv. Space Res., 27(10), 1653-1658.

Preusse, P., S. D. Eckermann, and M. Ern (2008), Transparency of the atmosphere to short horizontal wavelength gravity waves, J. Geophys. Res., 113, D24104, doi:10.1029/2007JD009682.

Preusse, P., S. D. Eckermann, M. Ern, J. Oberheide, R. H. Picard, R. G. Roble, M. Riese, J. M. Russell III, and M. G. Mlynczak (2009), Global ray tracing simulations of the SABER gravity wave climatology, J. Geophys. Res., 114, D08126, doi:10.1029/2008JD011214

Remedios, J. J., R. J. Leigh, A. M. Waterfall, D. P. Moore, H. Sembhi, I. Parkes, J. Greenhough, M. Chipperfield, and D. Hauglustaine (2007), MIPAS reference atmospheres and comparisons to V4.61/V4.62 MIPAS level 2 geophysical data sets, Atmos. Chem. Phys. Discuss., 7, 9973-10,017.

Salby, M. L., and R. R. Garcia (1987), Transient response to localized episodic heating in the tropics. Part I: Excitation and short-time near-field behavior, J. Atmos. Sci., 44(2), 458-498.

Sato, K. (1992), Vertical wind disturbances in the afternoon of midsummer revealed by the MU radar, Geophys. Res. Lett., 19(19), 1943-1946.

Sato, K. (1993), Small-scale wind disturbances observed by the MU radar during the passage of Typhoon Kelly, J. Atmos. Sci., 50(4), 518-537.

Sato, K., H. Hashiguchi, and S. Fukao (1995), Gravity waves and turbulence associated with cumulus convection observed with the UHF/VHF clear-air Doppler radars, J. Geophys. Res., 100(D4), 7111-7119.

Scaife, A. A., N. Butchart, C. D. Warner, D. Stainforth, and W. Norton (2000), Realistic quasi-biennial osciallations in a simulation of the global climate, Geophys. Res. Lett., 27(21), 3481-3484.

Sentman, D. D., et al. (2003), Simultaneous observations of mesospheric gravity waves and sprites generated by a midwestern thunderstorm, J. Atm. Sol. Terr. Phys., 65(5), 537-550.

Suzuki, S., K. Shiokawa, Y. Otsuka, T. Ogawa, K. Nakamura, and T. Nakamura (2007), A concentric gravity wave structure in the mesospheric airglow images, J. Geophys. Res., 112, D02102, doi:10.1029/ 2005JD006558.

Taylor, M. J., and M. A. Hapgood (1988), Identification of a thunderstorm as a source of short period gravity waves in the upper atmospheric nightglow emissions, Planet. Space Sci., 36(10), 975-985. 
Taylor, M. J., M. A. Hapgood, and P. Rothwell (1987), Observations of gravity wave propagation in the OI $(557.7 \mathrm{~nm}), \mathrm{Na}(589.2 \mathrm{~nm})$ and the near infrared $\mathrm{OH}$ nightglow emissions, Planet. Space Sci., 35(4), 413-427.

Tobin, D. C., et al. (2006), Radiometric and spectral validation of Atmospheric Infrared Sounder observations with the aircraft-based Scanning High-Resolution Interferometer Sounder, J. Geophys. Res., 111, D09S02, doi:10.1029/2005JD006094.

Uccellini, L. W., and S. E. Koch (1987), The synoptic setting and possible energy sources for mesoscale wave disturbances, Mon. Weather. Rev., 115(3), 721-729.

Walden, V. P., W. L. Roth, R. S. Stone, and B. Halter (2006), Radiometric validation of the Atmospheric Infrared Sounder over the Antarctic plateau, J. Geophys. Res., 111, D09S03, doi:10.1029/2005JD006357.

Wang, L., and M. A. Geller (2003), Morphology of gravity-wave energy as observed from 4 years (1998-2001) of high vertical resolution U.S. radiosonde data, J. Geophys. Res., 108(D16), 4489, doi:10.1029/ 2002JD002786.

Wu, D. L., and F. Zhang (2004), A study of mesoscale gravity waves over the North Atlantic with satellite observations and a mesoscale model, J. Geophys. Res., 109, D22104, doi:10.1029/2004JD005090.

Zhang, F. (2004), Generation of mesoscale gravity waves in uppertropospheric jet-front systems, J. Atmos. Sci., 61(4), 440-457.

M. J. Alexander, Colorado Research Associates Division, NorthWest Research Associates, Inc., 3380 Mitchell Ln., Boulder, CO 80301, USA. (alexand@cora.nwra.com)

L. Hoffmann, Institut für Chemie und Dynamik der Geosphäre, Forschungszentrum Jülich, Leo-Brandt-Str., D-52425 Jülich, Germany. (1.hoffmann@fz-juelich.de) 